\title{
Antiulcerogenic Activity of methanol extract and solvent fractions of Stem Bark of Lannea acida (A. Rich) Against Ethanol-Induced Gastric Mucosal Injury in Albino Rats
}

Onoshe Solomon ${ }^{a^{*}}$, Wasagu Rabiu Saidu Umara, Hassan Sanusi Waraa , Abubakar Sadiq Yakubub, Madusolumou Michael Azubuikec, Mbahi Asugu Maryd and Hitler Louis ${ }^{\mathbb{D}} \mathrm{e}^{*}$

a Department of Biochemistry, Usmanu Danfodiyo University, Sokoto, Nigeria.

b Department of Veterinary Medicine and Surgery, Usmanu Danfodiyo University, Sokoto, Nigeria.

c Department of Biochemistry, School of Life sciences, Modibbo Adama University of Technology, Yola, Nigeria.

d Department of Biological Sciences, Federal University Kashere, Gombe, Nigeria.

e CAS Key Laboratory of Nanosystem and Hierarchical Fabrication, CAS Centre for Excellence in Nanoscience, National

Centre for Nanoscience and Technology, University of Chinese Academy of Sciences, Beijing,P.R. China.

\section{H I G H L I G H T S}

- Pretreatment with the methanol extract and solvent fractions produce significant reductions in ulcer index in a dose dependent manner.

- Antiulcer activity of the EtyAc fraction was blocked upon coadministration with glibenclamide.

- The stem bark extract of Lannea acida possess antiulcerogenic activity seems to involve antioxidant activity
G R A P H I C A L A B S T RAC T

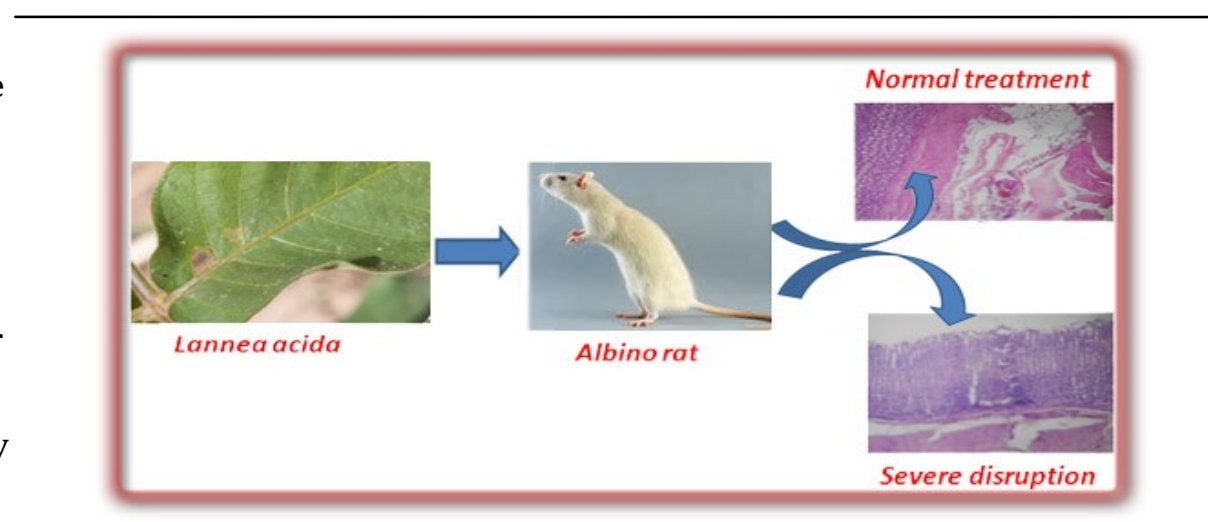

\section{AR T I C LE IN F O \\ Article history: \\ Received: 2018-11-12 \\ Revised: 2018-12-14 \\ Accepted: 2018-12-21 \\ Available online: 2019-01-03 \\ Manuscript ID: PCBR-1811-1004}

\author{
Keywords \\ Antiulcerogenic \\ Lannea acida \\ Mechanism, Ethanol \\ Gastric \\ Mucosal \\ Albino Rats
}

\begin{abstract}
A B S T R A C T
Peptic ulcer disease is one of the most prevalent gastrointestinal disorders causing tremendous human suffering worldwide. The present study was designed to evaluate the antiulcerogenic activity of the methanol and solvent stem bark fractions (hexane, ethyl acetate and butanol) and elucidate their possible antiulcerogenic mechanisms. The antiulcerogenic mechanisms were investigated by estimation of Superoxide dismutase (SOD), Glutathione (GSH), Catalase (CAT), Vitamins A, C and E, Malondialdehyde (MDA) and involvement of $\mathrm{K}_{\mathrm{ATP}}$ channel. Pretreatment with the methanol extract and solvent fractions produce significant reductions in ulcer index in a dose dependent manner. Ethylacetate fraction (EtyAc) showed the highest antiulcer activity. Elevated MDA and decreased levels of SOD, GSH, CAT, Vitamin A, C and $\mathrm{E}$ observed in ulcer control groups were significantly decreased and increased respectively in the EtyAc fraction treated groups. Antiulcer activity of the EtyAc fraction was blocked upon coadministration with glibenclamide; a $\mathrm{K}_{\mathrm{ATP}}$ channel blocker. The stem bark extract of Lannea acida possess antiulcerogenic activity and the mechanisms seems to involve antioxidant activity and $\mathrm{K}_{\mathrm{ATP}}$ channel opening.
\end{abstract}




\section{Introduction}

Peptic ulcer disease (PUD) is a problem of the gastrointestinal tract characterized by a break in the normal gastric mucosa integrity secondary to gastric acid and pepsin secretion[1]. It represents a serious and growing health problem in the whole world[2]. It has a worldwide prevalence of about $40 \%$ in the developed countries and $80 \%$ in the developing countries [3]. It is the most prevalent gastrointestinal disorder ever known, accounting for an estimated 15 mortalities out of every 15,000 complications yearly in the world. The disease develops as a result of altered balance between offensive and defensive factors. The major offensive factors are gastric acid secretion, pepsin secretion, non-steroidal antiinflammatory drugs (NSAIDs), Helicobacter pylori ( $H$. pylori) infection and bile salts. Defensive factors include the mucosal barrier, mucus secretion, prostaglandin, bicarbonate, blood flow, cellular regeneration, epidermal growth factors and motility [4, 5]. Stomach colonization by the bacterium $H$. pylori and indiscriminate use of NSAIDs are the two most prominent causes of PUD [6]. The most common symptoms of PUD include episodic epigastric pain or gnawing. During the last two decades, the use of plants for the prevention, treatment and/or management of PUD has been advocated. This is due to several reasons, namely, orthodox drugs provoke many adverse effects, perceived effectiveness, affordability, ease of accessibility and safety of medicinal plants. Moreover, a large percentage of the world's population does not have access to conventional pharmacological treatment [7]. Lannea acida is a small deciduous shrub or tree belonging to the family Anacardiaceae [8]. It is a valuable multi-purpose tree widely used by local people. The bark is used internally in the treatment of stomach troubles, beriberi, schistosomiasis and haemorrhoids (Burkill, 2004). The powdered root, mixed with salt, is made into a tampon for application to the scrotum in treating orchitis [9]. The kernel is purgative, applied externally, it is used to treat eye-troubles. The root bark is considered good for treating skin-infections. The leaves and bark have been reported to be useful in the treatment and management of gout, rheumatism, wounds, swelling and burns [9]. Lannea acida (A. Rich) is noted for being effective in the treatment of different ulcer cases among the Hausa and Fulani in Sokoto State, North Western, Nigeria [10]. To the best of our knowledge, a scientific investigation on the antiulcerogenic effect of this plant based on its folkloric use has not been evaluated. Therefore, the present study is designed to evaluate the antiulcerogenic effect of stem bark extract and solvent fractions of L. acida on ethanol induced mucosal injury in albino rats.

\section{Materials and Experimental Methods}

\subsection{Chemicals and Reagents}

Solvents for extraction and partitioning of the plant materials and all other chemicals were of analytical grades.

\subsection{Experimental Animals}

Albino rats weighing between 150-180g of both sexes were used for the study. The animals were obtained from the animal house of Department of Pharmacology and Toxicology, Usmanu Danfodiyo University, Sokoto. The rats were housed in clean and disinfected plastic cages and were allowed to acclimatize for fourteen (14) days. The rats were fed with a standard rat chow and allowed to drink water ad libitum. All experiments were carried out in accordance with the WHO guidelines for the use of experimental animals [11].

\subsection{Plant collection and identification}

The fresh stem bark of Lannea acida was collected from Zuru town in Kebbi State, Nigeria. The plant was authenticated by a taxonomist from Botany Unit in Biological Science Department, Usmanu Danfodiyo University Sokoto where a voucher specimen has been deposited.

\subsection{Preparation of Plant Extracts}

The preparation of extract was carried out according to the method of Hassan et al. [12]. Briefly, the stem bark of the plant collected was cleaned, air dried at room temperature and then cut into small pieces. Two hundred grams (200g) of it was macerated using 2L of $95 \%$ methanol for $48 \mathrm{hrs}$ and was filtered with Whatman sized 1 filter paper. The filtrate was concentrated in a rotary evaporator at $45^{\circ} \mathrm{C}$. The dried extract was kept in a dried clean air tight container until used.

\subsection{Fractionation of the extract}

This was carried out according to the method of Hassan et al. [12]. Exactly about fifty grams (50g) of the crude methanol stem bark residue was subjected to fractionation by solubilisation in water in a separatory funnel and sequential partition with hexane $(3 \times 200 \mathrm{~mL})$, ethyl acetate 
$(3 \times 200 \mathrm{~mL})$ and saturated butanol $(3 \times 200 \mathrm{~mL})$. Each fraction was evaporated to dryness and subjected to antiulcerogenic activity.

\subsection{Antiulcer Studies}

\subsubsection{Gastric Ulcer Induction by Ethanol}

The induction of gastric mucosal damage was carried out by the method of Almasaudi et al. [13]. Albino rats of either sex were divided into six (6) groups of five (5) animals each as follows: Group E1 (Control): rats in this group received distilled water only, Group E2 (Cimetidine): rats in this group received cimetidine at a dose of $100 \mathrm{mg} / \mathrm{kg}$ for seven days before the induction of ulcer, Group E3 (Positive Control): rats in this group received ethanol at a dose of $1 \mathrm{ml} / 200 \mathrm{~g}$ on the seventh day only, Group E4, E5 and E6: rats in this group received the plant extract at a dose of 100, 200 and $300 \mathrm{mg} / \mathrm{kg}$ respectively for 7 days before the induction of ulcer.

Following 24 hours of food deprivation on the seventh day, the standard drug and test substances were administered. One hour after the pretreatment, the animals were administered ethanol at a dose of $1 \mathrm{ml} / 200 \mathrm{~g}$ body weight by intragastric gavage. Sixty minutes later the rats were sacrificed. Immediately after sacrificing the animals, the stomachs were removed, cut along the greater curvature and the mucosa was washed with $0.9 \%$ saline solution to clean away the blood. This was followed by macroscopic examination of the stomach for the detection of any hemorrhagic lesions on the glandular mucosa.

\subsubsection{Measurement of Ulcer Score}

The ulcer score was determined by scoring of severity of mucosal lesions as reported by Almasaudi et al. [13]. This was done as follows: no ulcer (0), small ulcer (1-2 $\mathrm{mm}$ ) (1), medium ulcer (3-4 mm) (2), large ulcer (5-6 mm) (4) and huge ulcer (>6 mm) (8).

\subsubsection{Measurement of Ulcer Index}

Measurement of ulcer index was carried out as reported by Ugwah et al. [14] and Wasagu and Shehu [15]. The average of the length in $\mathrm{mm}$ of all lesions for each stomach was measured to determine the mean ulcer index (UI).

$$
\text { Ulcer Index (UI) = UN + US + UP X 10-1 }
$$

Where; UN = Average of number of ulcer per animal, US $=$ Average of severity score

UP = Percentage of animal with ulcer

\subsubsection{Measurement of Percentage Inhibition}

The percentage inhibition was calculated using the method of Mahmood et al. [16].

$$
\% \text { inhibition }=\frac{\text { UI of control }- \text { UI Of test }}{\text { UI of control }} \times 100
$$

\subsubsection{Histological Evaluation of Gastric Lesions}

For histopathological examination, the tissues were fixed in $10 \%$ formalin solution. Then, the formalin-fixed stomach specimens were embedded in paraffin wax and serially sectioned (3-5 $\mu \mathrm{m})$ and further stained with hematoxylin and eosin. The stained tissues were observed for pathological changes using light microscopy [13].

\subsection{Antiulcer Activity of Solvent fractions}

The solvent fractions were tested for antiulcer activity using the ethanol model described earlier. Albino rats of either sex were divided into seven (7) groups of five (5) animals each as follows: SF I: rats in this group received distilled water only, SF II: rats in this group received cimetidine at a dose of $100 \mathrm{mg} / \mathrm{kg}$ for seven days before the induction of ulcer, SF III: rats in this group received ethanol at a dose of $1 \mathrm{ml} / 200 \mathrm{~g}$ on the seventh day only, $\mathbf{S F}$ IV-VII: rats in this group received hexane, ethylacetate, butanol and last remaining aqueous fraction at a dose of $300 \mathrm{mg} / \mathrm{kg}$ for 7 days before the induction of ulcer. Induction of ulcer and measurement of ulcer score, ulcer index, percentage inhibition and histological examination of gastric tissues were carried out as described above.

2.8 Mechanism of Antiulcer Activity of the Most Potent Solvent Fraction (MPSF)

A frozen portion of the stomachs was thawed. Thawed tissues were homogenized in $50 \mathrm{Mm}$ potassium phosphate, pH 7.5 and 1Mm EDTA.

\section{Antioxidant Activity of Gastric Homogenate}

Catalase activity, reduced glutathione, malondialdehyde (MDA), superoxide dismutase activity, Vitamin A, Vitamin C and Vitamin E were estimated by the method which is described in previous papers [17-24]. 


\subsection{Evaluation of the Involvement of $K_{A T P}$ Channels}

To study the possible involvement of $\mathrm{K}_{\mathrm{ATP}}$ channel in the antiulcer activity of the MPSF; a separate experiment was conducted. Albino rats of either sex were divided into six (6) groups designated control, ethanol, ethanol and EtyAc, ethanol and glibenclamide, Ethanol+EtyAc+Glibenclamide, and Ethanol+Drug. The treatment groups were pretreated with the EtyAc fraction. Thirty minutes after, the animals were administered with glibenclamide a blocker of $\mathrm{K}_{\mathrm{ATP}}$ channels $(6 \mathrm{mg} / \mathrm{kg})$. After another $30 \mathrm{mins}$, all animals received absolute ethanol $(1 \mathrm{ml} / 200 \mathrm{~g})$ for the ulcer induction. Sixty minutes after the administration of ethanol, the rats were sacrificed, and their stomachs removed for examination, as previously described.

\subsection{Data Analysis}

All data was reported as means \pm standard error of mean (SEM). The values were analyzed using Statistical Package for Social Sciences (SPSS) windows program version 20. Statistical significance of difference between means was carried out using one-way analysis of variance (ANOVA). $p<0.05$ was considered significant.

\section{Results}

\subsection{Anti-Ulcerogenic Studies of the Crude Extract}

Oral administration of absolute ethanol produced mucosal lesions in the albino rats (Table 1). The gastric mucosal lesions produced in the ulcer control group; marked by elevated ulcer index were very extensive. Pretreatment with 100, 200 and $300 \mathrm{mg} / \mathrm{kg}$ of the methanol solvent extact, demonstrated significant reductions in ulcer index $(p<0.05)$ in a dose dependent manner when compared to the ethanol ulcer control group. The standard drug; cimetidine $(100 \mathrm{mg} / \mathrm{kg})$ showed less mucosal injury with significant $(p<0.05)$ reductions in ulcer index. The reductions in ulcer index produced by the extract at 200 and $300 \mathrm{mg} / \mathrm{kg}$ was comparable with that of the standard drug. Although, the extract at $100 \mathrm{mg} / \mathrm{kg}$ showed significant reductions in ulcer index, the values were far less when compared with the reference drug.

This result was confirmed after histological examination as shown in Fig. 1A-F. In the ethanol ulcer control group, there were severe disruptions, erosion and vacoulation of the stomach glands with infiltration of inflammatory cells (Fig. 1B).
Table 1: Effect of Different Doses of Methanol Stem bark Extract of Lannea acida and Cimetidine on Ethanol-Induced Ulcer in Rats.

\begin{tabular}{ccccc}
\hline $\begin{array}{c}\text { Gr } \\
\text { oups }\end{array}$ & $\begin{array}{c}\text { Treatm } \\
\text { ent }\end{array}$ & $\begin{array}{c}\text { Dose } \\
(\mathrm{mg} / \mathrm{kg})\end{array}$ & $\begin{array}{c}\text { Ulcer } \\
\text { Index }\end{array}$ & $\begin{array}{c}\% \\
\text { Protection }\end{array}$ \\
\hline E1 & $\begin{array}{c}\text { Normal } \\
\text { Control }\end{array}$ & - & $0.00 \pm 0.0$ & 100 \\
& & 0 & \\
E2 & Ulcer & $1 \mathrm{ml} / 2$ & $\begin{array}{c}12.28 \pm 0 . \\
38^{* *}\end{array}$ & - \\
& Control & $00 \mathrm{~g}$ & & \\
E3 & Cimetid & 100 & $2.75 \pm 0.1$ & 77.61 \\
& ine & & $0^{*}$ & \\
E4 & MSELA & 100 & $7.52 \pm 0.0$ & 38.76 \\
& & & $9^{*}$ & \\
E5 & MSELA & 200 & $5.48 \pm 0.1$ & 55.37 \\
& & & $7^{*}$ & \\
E6 & MSELA & 300 & $3.73 \pm 0.1$ & 69.63 \\
& & & $7^{*}$ & \\
\end{tabular}

Values are expressed as Mean \pm SEM $(n=4)$.

${ }^{*} p<0.05$ : Significantly different when compared to ulcer group; ${ }^{* *} p<0.05$ : Significantly different when compared to normal group (One-Way ANOVA followed by Dunnett Multiple Comparison Test Using SPSS Version 20). MSELA: Methanol Stem Bark Extract of Lannea acida.

The rats pretreated with 100, 200 and $300 \mathrm{mg} / \mathrm{kg}$ showed markedly better reductions in gastric lesion evident by moderate sloughing of epithelian infiltration and vacoulation, severe fibrous connective tissue formation suggestive of healing process and normal glandular stomach (Fig. 1D-F). The drug control group demonstrated significantly better mucosal protection with less mucosal damage and massive fibrous connective tissue formation (Fig. 1C).

\subsection{Anti-Ulcerogenic Activity of Solvent Fractions}

The solvent fractions (Hexane, Ethylacetate, Saturated Butanol and Last Remaining Aqueous Fraction) significantly mitigated the development of gastric lesions and significantly $(p<0.05)$ decreased ulcer index when compared to the ethanol ulcer control group (Table 2). EtyAc fraction was the most potent solvent; accomplishing similar efficacy to the standard drug. Least reduction in ulcer index was observed in the hexane fraction treated group. Rats administered with ethanol showed marked increase in ulcer index when compared to the normal control group. 

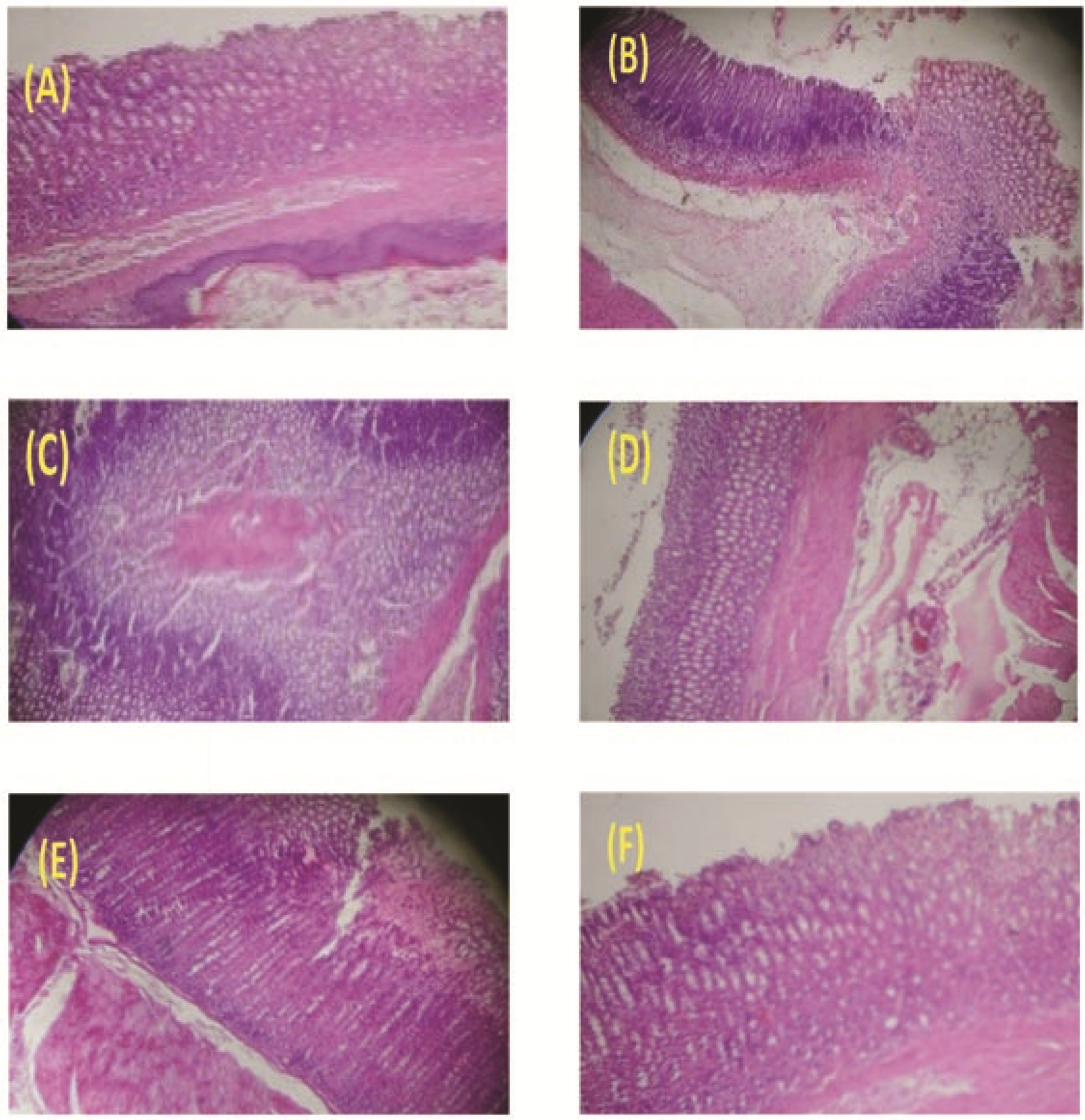

Fig. 1- NORMAL Control. Normal Glandular Stomach (palte A), Ethanol Ulcer Control showing severe disruption, erosion and vacoulation of the stomach glands with infiltration of inflammatory cells (palte B), Cimetidine Control showing Massive Fibrous Connective Tissue Formation with cellular infiltration and vascular congestion (palte C), 100mg/kg of MSELA. Showing congestion, moderate sloughing of epithelium and vacoulation (H\&E stain, 20x magnification) (palte D), 200mg/kg of MSELA with Massive fibrous connective tissue formation, infiltration of inflammatory exudattes and congested blood vessels (palte E), $300 \mathrm{mg} / \mathrm{kg}$ of MSELA showing Normal glandular stomach (palte F). 

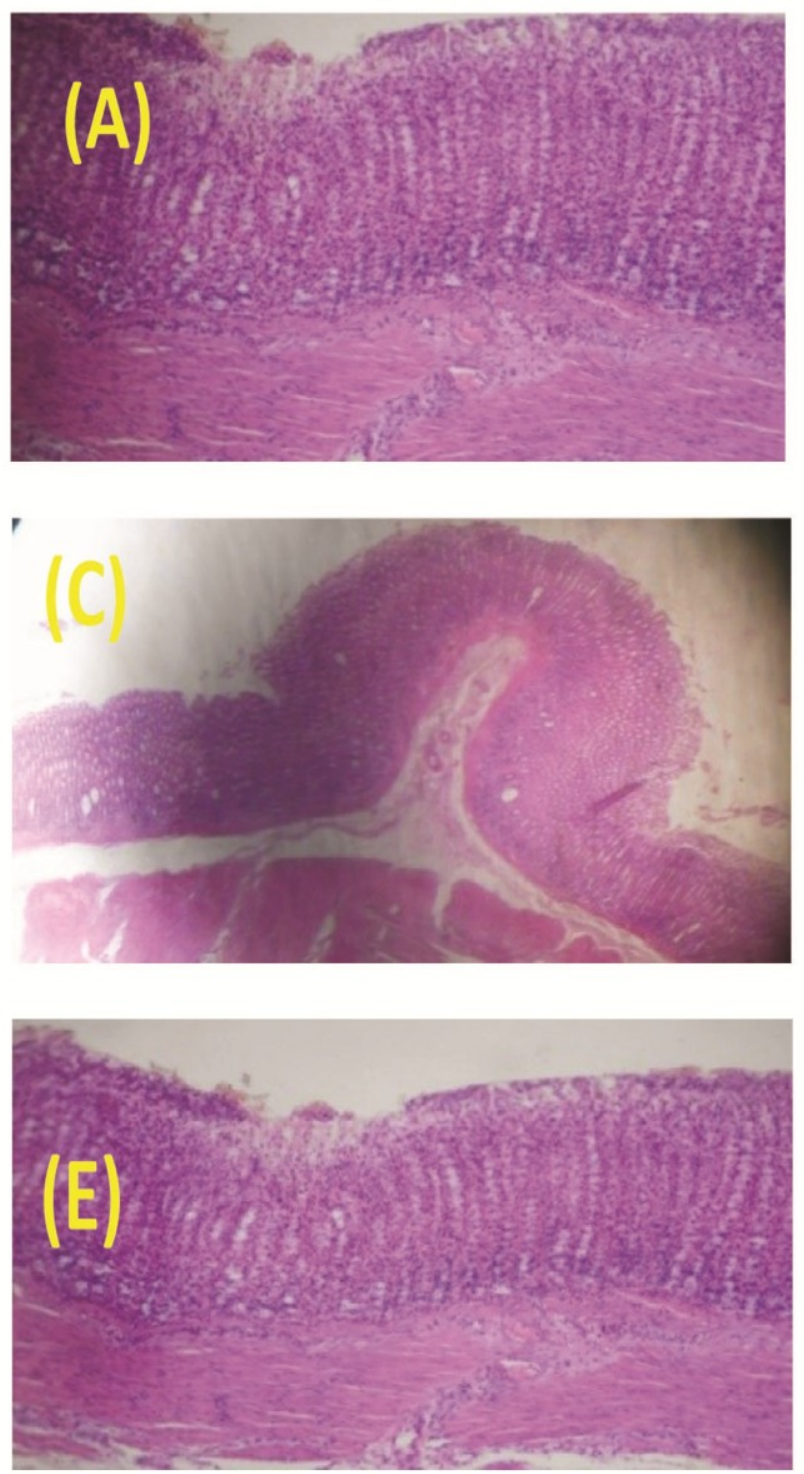
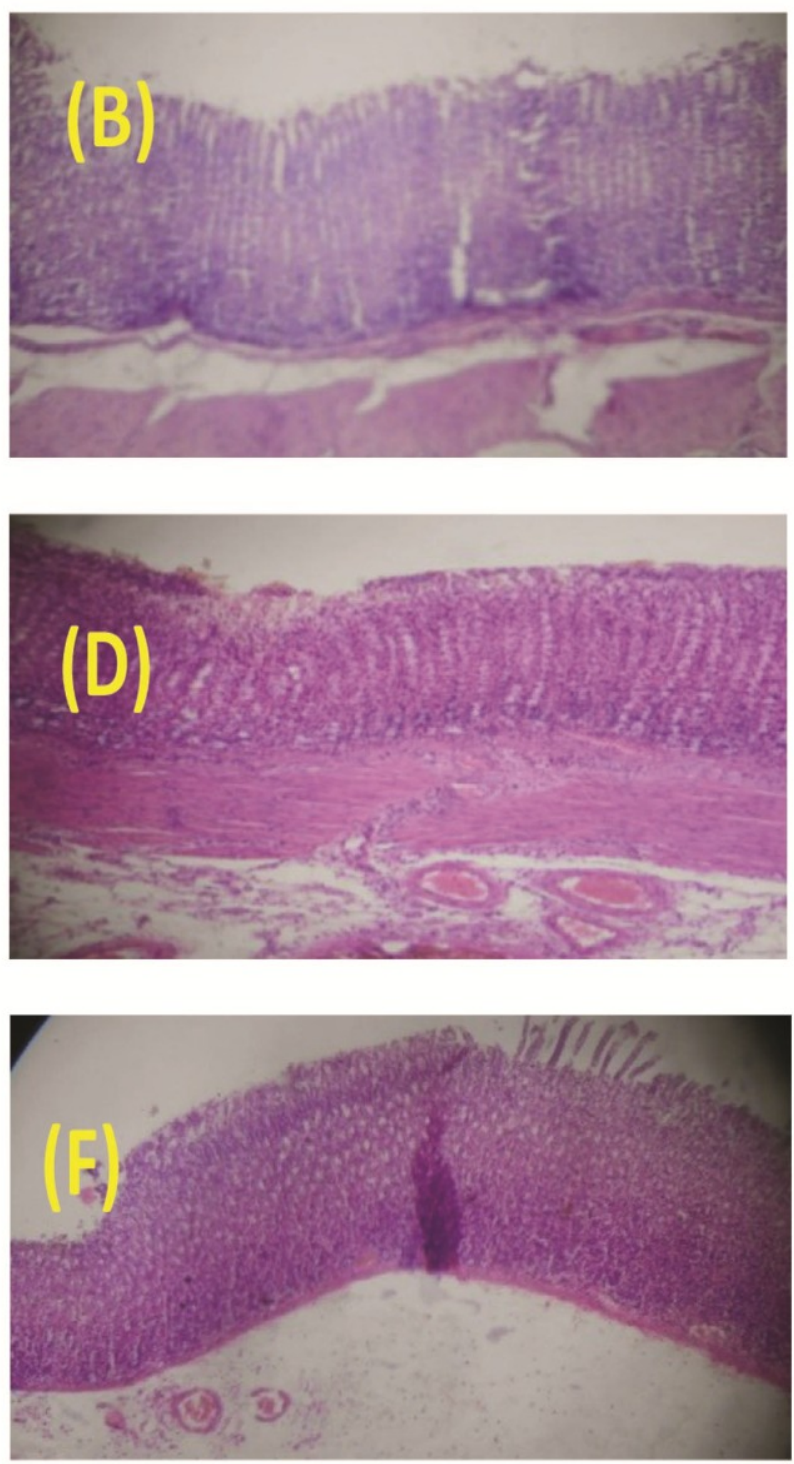

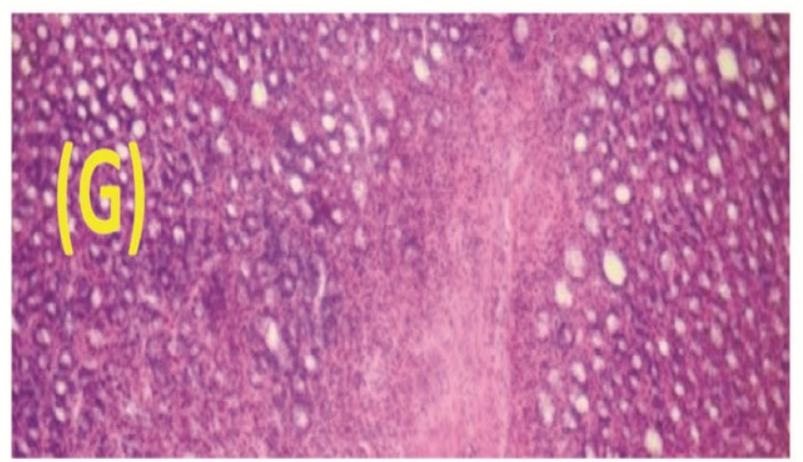

Fig. 2- NORMAL Control. Normal Glandular Stomach (palte A), Ethanol Ulcer Control showing severe disruption and erosion of the gastric pits (palte B), Cimetidine Control showing normal glandular stomach (palte C), HEX Treated group showing normal glandular stomach with severe vascular congestion in the submucosal surface (palte D), EtyAc Treated group showing near normal glandular stomach (palte E), BuOH Treated group showing normal glandular stomach with mild vascular congestion (palte F), LRAF Treated group showing connective tissue formation suggesting healing process (palte $\mathrm{G}$ ), 
Table 2: Effect of Different Solvent Fractions of MSELA and Cimetidine on Ethanol-Induced Ulcer in Rats.

\begin{tabular}{lllll}
\hline Groups & Treatment & $\begin{array}{l}\text { Dose } \\
(\mathrm{mg} / \mathrm{kg})\end{array}$ & Ulcer Index & $\begin{array}{l}\% \\
\text { Protection }\end{array}$ \\
\hline SF I & Normal & - & 00.00 & 100 \\
SF II & Ulcer & $1 \mathrm{ml} / 200 \mathrm{~g}$ & $12.95 \pm 0.48^{* *}$ & - \\
SF III & Cimetidine & 100 & $2.63 \pm 0.17^{*}$ & 79.69 \\
SF IV & HEX & 300 & $6.18 \pm 0.30^{*}$ & 52.28 \\
SF V & EtyAc & 300 & $3.11 \pm 0.10^{*}$ & 75.98 \\
SF VI & BuOH & 300 & $4.01 \pm 0.08^{*}$ & 69.03 \\
SF VII & LRAF & 300 & $5.53 \pm 0.10^{*}$ & 57.30
\end{tabular}

Values are expressed as Mean \pm SEM $(n=4)$.

${ }^{*} p<0.05$ : Significantly different when compared to ulcer group;

${ }^{* *} p<0.05$ : Significantly different when compared to normal group (One-Way ANOVA followed by Dunnett Multiple Comparison Test Using SPSS Version 20).

HEX: Hexane Fraction, EtyAc: Ethylacetate Fraction, BuOH: Saturated Butanol Fraction and LRAF: Last Remaining Aqueous Fraction

The findings of histopathological analysis of the solvent fractions is summarised in Fig. 2A-G. The mucosa layer of the stomach of the control rats showed normal histology with intact epithelial lining and gastric pits (Fig. 2A). The rats treated with ethanol showed severe disruption and erosion of the gastric pits (Fig. 2B). The rats treated with cimetidine showed no ulceration evident by normal glandular stomach (Fig 2C). Near normal stomach mucosa to normal glandular stomach with massive formation of connective tissue suggestive of healing were observed in the rats treated with HEX, EtyAc, BuOH and LRAF (Fig 2DG).

\subsection{Mechanism of Action}

\subsubsection{In-vivo Antioxidant Activity}

In an attempt to investigate the possible mechanism involved in the antiulcerogenic activity, the level of antioxidant enzymes; GSH, SOD, CAT, and MDA; an index of lipid peroxidation were evaluated. The results showed that rats administered with ethanol had marked significant $(p<0.05)$ reductions in the level of GSH, activities of SOD, CAT, and an increased MDA compared to normal. Pretreatment with the EtyAc fraction significantly increased the level of GSH, SOD and CAT activities. It also significantly decreased the level of MDA when compared to the ethanol induced ulcer control group (Tables 3). Similarly, rats pretreated with the standard drug had significantly $(p<0.05)$ increased level of GSH, SOD and CAT activities and decreased levels of MDA. The increased level of GSH, SOD and CAT activities and decrease in the level of MDA observed in the EtyAc pretreated groups were comparable with that of the normal and the standard drug control group.

\subsection{Investigation of the Involvement of $K_{\text {ATP }}$ Channels in} the Antiulcerogenic Activity of the EtyAc fraction

The result of involvement of $K_{\text {ATP }}$ channels in the antiulcerogenic activity of the EtyAc fraction is shown in Fig. 3. Ethanol induced marked ulcerative lesions as observed earlier.

Table 3: Effect of the EtyAc Fraction of Lannea acida on in-vivo antioxidants in Ethanol Induced Ulcer

\begin{tabular}{lccccccc}
\hline \multicolumn{1}{c}{ Group } & $\begin{array}{c}\text { MDA } \\
\text { (nmol/mg } \\
\text { protein) }\end{array}$ & $\begin{array}{c}\text { GSH } \\
\text { (mM/mg } \\
\text { protein) }\end{array}$ & $\begin{array}{c}\text { SOD } \\
\text { (U/mg } \\
\text { protein) }\end{array}$ & $\begin{array}{c}\text { CAT } \\
\text { (U/mg } / \mathrm{mg} \\
\text { proin) }\end{array}$ & $\begin{array}{c}\text { A } \\
(\mu \mathrm{mol} / \mathrm{mg} \\
\text { tissue) }\end{array}$ & $\begin{array}{c}\mathrm{C} \\
(\mu \mathrm{mol} / \mathrm{mg} \\
\text { tissue) }\end{array}$ & $\begin{array}{c}\mathrm{E} \\
(\mu \mathrm{mol} / \mathrm{mg} \\
\text { tissue) }\end{array}$ \\
\hline Normal & $3.54 \pm 0.29^{*}$ & $47.16 \pm 2.96^{*}$ & $4.61 \pm 0.21^{*}$ & $62.31 \pm 3.29^{*}$ & $1.77 \pm 0.21^{*}$ & $1.91 \pm 0.01^{*}$ & $0.87 \pm 0.06^{*}$ \\
Et0H & $6.59 \pm 0.73^{* *}$ & $28.26 \pm 4.23^{* *}$ & $3.44 \pm 0.24^{* *}$ & $42.94 \pm 2.61^{* *}$ & $0.61 \pm 0.04^{* *}$ & $1.04 \pm 0.14^{* *}$ & $0.56 \pm 0.03^{* *}$ \\
Control & & & & & & & \\
Cimetidine & $3.77 \pm 0.19^{*}$ & $43.99 \pm 0.92^{*}$ & $5.08 \pm 0.12^{*}$ & $61.39 \pm 0.57^{*}$ & $1.47 \pm 0.20^{*}$ & $1.38 \pm 0.25^{*}$ & $0.79 \pm 0.92^{*}$ \\
EtyAc & $2.99 \pm 0.07^{*}$ & $44.96 \pm 2.28^{*}$ & $4.88 \pm 0.22^{*}$ & $60.85 \pm 2.71^{*}$ & $1.33 \pm 0.30^{*}$ & $1.88 \pm 0.13^{*}$ & $0.64 \pm 0.20^{*}$
\end{tabular}

Values are expressed as Mean \pm SEM ( $\mathrm{n}=4)$. Mean having different Superscript in a column are significantly different $(p<0.05)$ (One-Way ANOVA followed by Dunnett's Multiple Comparison Test Using SPSS Version 20). EtyAc: Ethylacetate Fraction. 


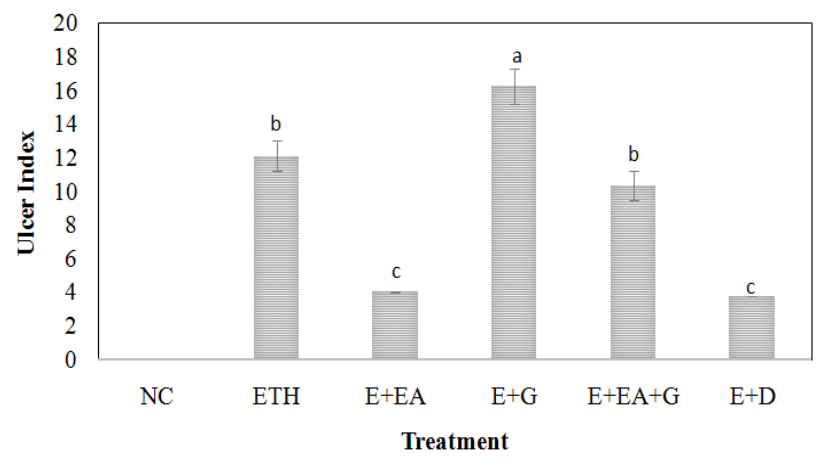

Fig, 3: Effect of EtyAc on involvement of $\mathrm{K}_{\mathrm{ATP}}$ channel on Ethanol Induced Ulcer. Key: NC-Normal Control, ETH Ethanol, E + G - Ethanol + Glibenclamide, E + EA + GEthanol+ EtyAc + Glibenclamide, E + D - Ethanol + Drug. Bars with Different Supercripts are significantly different $(p<0.05)$

Glibenclamide significantly aggravated gastric lesions formation, EtyAc alone demonstrated antiulcerogenic activity with significant reduction in ulcer index when compared with control and coadministration of the EtyAc fraction with glibenclamide abolished the antiulcerogenic effect afforded by the EtyAc fraction evident by significant increase in ulcer index.

\section{Discussion}

\subsection{Antiulcer}

The quest to conquer peptic ulcer disease has led to the evaluation of a number of plant for possible antiulcerogenic activity. Several experimental gastric ulcer induction models in animals have been widely used for this purpose [25]. In the present study, ethanol ulcer induction model was employed.

The oral administration of ethanol resulted in marked increase in ulcer index with severe congestion and haemorrhages in the epithelial, sloughing and disruption of gastric pits and infiltration of inflammatory cells. Severe erosion and vacoulation of the stomach glands were also observed. The formation of gastric mucosal lesions following ethanol administration involves several mechanisms such as production of reactive oxygen species which culminates in the reduction of mucosal non-protein sulfylhydryl level, reduction in gastric blood flow, solubilization of mucus constituents and increase in xanthine oxidase activity [26]. It also produces necrotic lesions in the gastric mucosa of animals by a direct toxic effect thereby reducing the secretion of bicarbonates and depleting gastric mucus production in animals. Earlier studies revealed that ethanol induces gastric mucosal injury by causing extensive damage to mucosal capillaries resulting in increased vascular permeability, oedema formation and epithelial lifting $[27,28]$. Ethanol is also known to reduce effectively endogenous derived nitric oxide (NO) level in the gastric mucosa [29]. NO is considered to be one of the most important defensive endogenous agents in the gastric mucosa [30] also reported that ethanol cause gastric mucosal lesions through vasoconstriction, the release of vasoactive substances such as histamine, and the production of free radicals that cause a discontinuity in the mucosal cell membrane. In this study, administration of methanol extract and solvent fractions of stem bark of Lannea acida prior to induction of ulcer protected the rats against ethanol ulcerogenesis. EtyAc fraction showed the highest activity and offered better protection. The results are in agreement with other studies, where plant extracts have been shown to prevent gastric mucosal ulceration in rats using the ethanol model $[16,31]$. The protection offered by the extract and its fractions can be linked to increase secretion of bicarbonate, production of mucus and decrease in vascular permeability. Previous studies have also shown that administration of antioxidants can inhibit ethanol induced gastric damage [32, 33]. The significant decrease in ulcer index observed may also be indicative of the ability of the extract and its fraction to scavenge generated free radicals and toxic metabolites.

\subsection{Mechanism of Action}

In order to elicit the possible antiulcerogenic mechanism of methanol and solvent fractions of stem bark of Lannea acida in albino rats, the effect of EtyAc fraction on lipid peroxidation and antioxidant enzymes and vitamins levels were investigated. The effect of glibenclamide a $K_{\mathrm{ATP}}$ channel blocker on the protection offered by the EtyAc fraction was also evaluated.

\subsection{Lipid Peroxidation}

Oxidative stress plays an important role in the pathogenesis of various diseases including peptic ulcer disease [34]. Malondialdehyde (MDA) the end product of lipid peroxidation acts as a marker of oxidative stress [35]. It is an organic compound that results from the degradation of polyunsaturated lipid. MDA is a highly reactive substance and toxic to the living cells. In the 
present study the level of MDA was significantly increased the control group. Previous studies have reported the elevation of gastric mucosal MDA in ethanol induced ulcer $[34,36,37]$. The elevation could have resulted from peroxidation of a polyunsaturated fatty acid component of the membrane by generated free and oxygen-derived radicals [38]. Peroxidation of membrane lipids is associated with loss of membrane fluidity, impaired ion transport and membrane integrity and ultimately a loss of cellular function [36]. Pretreatment of the animals with EtyAc significantly reduced the level of MDA when compared to the control. This observation was suggestive of the ability of the EtyAc fraction to prevent the formation of ROS and subsequently inhibit lipid peroxidation of stomach tissue.

\subsection{Antioxidant Enzymes and Vitamins}

Antioxidants have being reported to not only play a significant role in the protection of gastric mucosal injury but also in inhibiting the progression of gastric ulcer [39]. In the present study, ethanol induction decreased the levels of gastric GSH, SOD and CAT activities indicating increased oxidative stress. Vitamin A, C and E levels were also significantly decreased. These results are in accordance with several previous reports [33, 40, 41]. GSH, SOD and CAT constitute mutually a supportive team of defense against reactive oxygen species. GSH is a major low molecular weight scavenger of free radicals in the cytoplasm and an important inhibitor of free radical mediated lipid peroxidation [42]. GSH in tissues has been proposed to be a potential chemopreventive agent due to its antioxidant and detoxification properties. Reduced GSH plays pleiotropic role, including maintaining cells in a reduced state and serving as an electron donor for certain free radical scavenging enzymes [43]. SOD is a metalloprotein that catalyses the dismutation of superoxide radicals. It is essential to the body in order to counteract the harmful effects of ROS from the cellular environment[44]. The hemeprotein; catalase catalyses the reduction of $\mathrm{H}_{2} \mathrm{O}_{2}$ to water and oxygen and thus protects the cell from oxidative damage by $\mathrm{H}_{2} \mathrm{O}_{2}$ and $\mathrm{OH}$ [45]. Vitamin $\mathrm{C}$ protects cells against various water-soluble radicals. It is a marker of oxidative stress and its reduced levels are in accordance with enhanced oxidative stress [46]. Vitamin E is a non-enzymatic antioxidant which effectively reacts with organic lipid radicals produced in the process of lipid peroxidation. The significant decrease in the level of GSH, activity of SOD and CAT and in the level of Vitamin A, C and $\mathrm{E}$ in tissue homogenate may be due to increased production of reactive oxygen radicals resulting in increased utilization of the these enzymes and vitamins [47]. Administration of the EtyAc fraction of Lannea acida resulted in a significant increase in the level of GSH, activities of SOD and CAT and in the level of Vitamin A, C and $\mathrm{E}$ as compared to the control animals. The significant reduction in MDA level coupled with increase in the level of GSH, activities of SOD and CAT in addition to increase in the levels of vitamin A, C and E clearly points to an antioxidant activity and strongly suggest involvement of antioxidative mechanism underlying the antiulcerogenic activity of the EtyAc fraction of stem bark extract of Lannea acida.

\subsection{Involvement of $K_{A T P}$ Channel}

It has been postulated that $\mathrm{K}_{\mathrm{ATP}}$ channels are involved in a variety of pathophysiological functions in the stomach such as regulation of blood flow, gastric acid secretion, and gastric muscle contractility [48]. In the vascular system, these channels are related to the relaxation of vascular smooth muscle, having an important role in blood pressure control. This vasodilation can be blocked by glibenclamide, a sulfonylurea that blocks $\mathrm{K}_{\mathrm{ATP}}$ channels [49]. The results of the involvement of $K_{A T P}$ channel showed that ethanol resulted in significant increase in ulcer index and was aggravated by coadministration with glibenclamide. The EtyAc fraction administered orally significantly reduced the ulcer index, however, the reduction in ulcer index was abolished when coadministered with glibenclamide (Fig. 3). These results suggest that the EtyAc fraction possesses an antiulcerogenic activity that depends, partly on its ability to open the $\mathrm{K}_{\mathrm{ATP}}$ channel. The antiulcerogenic activity of different $\mathrm{K}_{\mathrm{ATP}}$ channel openers like nicorandil, diazoxide and cromakalim have been demonstrated [48, $50,51]$. The mechanism by which $\mathrm{K}_{\mathrm{ATP}}$ channel opening; results in gastroprotection is still not fully known, but $\mathrm{K}_{\mathrm{ATP}}$ channel modulation has been reported to influence smooth muscle motility and gastric mucosal blood flow, two factors that are suggested to contribute significantly to ulcer lesions formation [52]. Therefore, $\mathrm{K}_{\mathrm{ATP}}$ channel openers, by preventing gastric hypermotility and by increasing gastric mucosal blood flow (and thus increasing oxygen and nutrient delivery to tissues allowing more resistance to injury), may protect the gastric mucosa against ulcer formation.

\section{Conclusion}

The methanol and solvent fractions of stem bark of Lannea acida possess antiulcerogenic activity. EtyAc fraction was the most potent. It's possible antiulcerogenic 
activity involved antioxidant activity via free radical scavenging and $\mathrm{K}_{\mathrm{ATP}}$ channel opening. Structural elucidation of the active principle (s) of the EtyAc fraction responsible for its antiulcerogenic activity is recommended for future work.

\section{Abreviations}

SOD: Superoxide dismutase

GSH: Glutathione

CAT: Catalase

MDA: Malondialdehyde

PUD: Peptic ulcer disease

NSAIDs: Non-steroidal anti-inflammatory drugs

\section{Declaration}

\subsection{Competing interests}

Authors declare no competing interests

\subsection{Funding}

No availanle source for funding

\subsection{Authors' contributions}

This research work was jointly design by Wasagu Rabiu Saidu Umar, Hassan Sanusi Wara, Abubakar Sadiq Yakubu and Madusolumou Michael Azubuike. Proper laboratory research and first manuscript draft was done by Onoshe Solomon while Mbahi Asugu Mary and Hitler Louis are collaborators.

\section{Acknowledgements}

We are thankful to all the members of staff of the Department Biological Sciences and of Pharmacology and Toxicology, Usmanu Danfodiyo University, Sokoto.

\section{References}

[1] K. Ramakrishnan and R.C. Salinas. Am. Fam. Physician., 2007, 76, 1005-10012.

[2] S. Sen, R. Chakraborty, B. De and J. Mazumder. Pharmacognosy Reviews, 2009, 3, 270-279.

[3] M.B. Adinortey, C. Ansah, I. Galyuon and A. Nyarko. Hindawi Publishing Corporation, 2013, 13, 112.

[4] F. Borrelli and A.A. Izzo. Phytotherapy Research: An International Journal Devoted to Pharmacological and Toxicological Evaluation of Natural Product Derivatives, 2000, 14, 581-591.
[5] C. Sostres, C.J. Gargallo, M.T. Arroyo and A. Lanas. Best Pract Res Clin Gastroenterol, 2010, 24, 121-32.

[6] J.C. Zapata-Colindres, S. Zepeda-Gómez, A. MontañoLoza, E. Vázquez-Ballesteros, J. de Jesús Villalobos and F. Valdovinos-Andraca. Canadian Journal of Gastroenterology and Hepatology, 2006, 20, 277280.

[7] S.M.K. Rates. Toxicon, 2001, 39, 603-613.

[8] L. Gill. Benin: Uniben Press ix, 1992.

[9] H. Ellenberg, A. Galat-Luong, H. von Maydell, M. Mühlenberg, K. Panzer, R. Schmidt-Lorenz, M. Sumser and T. Szolnoki. Gambian Press, , 1988, 2, 456.

[10] A.C. Oluranti, U.O. Michael, U. Jane and N.A. Ayembe. Int. Res. J. Pharm. Pharmacol, 2012, 2, 225-230.

[11] W.H. Organization. 2011, Geneva: World Health Organization.

[12] S.W. Hassanshy, S. Verma, S.K. Srivastava, S. Luqman, U. Gupta and N. Masood. African Journal of Biotechnology, 2013, 12, 6315-6325.

[13] S.B. Almasaudi, N.A. El-Shitany, A.T. Abbas, U.A. Abdel-dayem, S.S. Ali, S.K. Al Jaouni and S. Harakeh. Oxidative medicine and cellular longevity, 2016, 2016.

[14] M.O. Ugwah, E.U. Etuk, S.O. Bello, A.A. Aliero and C.J. Ugwah-Oguejiofor. Journal of Medicinal Plants Research, 2013, 7, 490-495.

[15] W.R.S. Umar and M.N. Shehu. Journal of Pharmacognosy and Phytochemistry, 2016, 5, 80.

[16] A. Mahmood, A.-B. Fouad, S. Noor, S. Wasman and S.F. Hussain. Journal of Medicinal Plants Research, 2011, 5, 5577-5583.

[17] A.K. Sinha. Analytical Biochemistry, 1972, 47, 389-394.

[18] G.L. Ellman. Archives of biochemistry and biophysics, 1959, 82, 70-77.

[19] P.E. Hartman. Environmental Mutagenesis, 1983, 5, 111-121.

[20] P. Kakkar, B. Das and P. Viswanathan. Indian J. Biochem. Biophys. , 1984, 21, 132.

[21] M. Rutkowski, K. Grzegorczyk, E. Gendek and J. Kedziora. Physiol. Pharm, 2006, 57, 221.

[22] P. Leelavinothan and S. Kalist. Eur Rev Med Pharmacol Sci, 2011, 15, 992-1002.

[23] I.D. Desai, [16] Vitamin E analysis methods for animal tissues, in Methods in enzymology. 1984, Elsevier. 138-147.

[24] R. Jalilian and A. Taheri. e-Polymers, 2018, 18, 123 134.

[25] M.S. Sheeba and V.V. Asha. Journal of Ethnopharmacology, 2006, 106, 105-110.

[26] P.C. Gupta, C.V. Rao and N. Sharma. Pharmaceutical biology, 2013, 51, 595-600.

[27] S. Kato, T. Kawase, J. Alderman, N. Inatomi and C.S. Lieber. Gastroenterology, 1990, 98, 203-210. 
[28] S. Szabo, J.S. Trier, A. Brown and J. Schnoor. Gastroenterology, 1985, 88, 228-36.

[29] H. Matsuda, Y. Li, T. Murakami, J. Yamahara and M. Yoshikawa. Life Sci, 1998, 63, P1245-50.

[30] V. Lambole and U. Kumar. International Journal of Biomedical Research, 2011, 2, 548-553.

[31] S.S. Al-Rejaie, H.M. Abuohashish, M.M. Ahmed, A.M. Aleisa and O. Alkhamees. Pharmaceutical biology, 2012, 50, 1542-1550.

[32] M. Abdulla, F. Al-Bayaty, L. Younis and M.A. Hassan. Journal of medicinal plants research, 2010, 4, 1253 1259.

[33] L.M.S. Lemos, T.B. Martins, G.H. Tanajura, V.F. Gazoni, J. Bonaldo, C.L. Strada, M.G. da Silva, E.L. Dall'Oglio, P.T. de Sousa Júnior and D.T. de Oliveira Martins. Journal of ethnopharmacology, 2012, 141, 432-439.

[34] F. Marotta, H. Tajiri, P. Safran, E. Fesce and G. Ideo. Digestion, 1999, 60, 538-543.

[35] E. Niki. Biofactors, 2008, 34, 171-180.

[36] T. Miura, S. Muraoka and Y. Fujimoto. Biochem Pharmacol, 2002, 63, 2069-74.

[37] P.R. Orsi, L.N. Seito and L.C. Di Stasi. Journal of ethnopharmacology, 2014, 151, 380-385.

[38] M. Ishii, S. Shimizu, S. Nawata, Y. Kiuchi and T. Yamamoto. Digestive diseases and sciences, 2000, 45, 93-98.

[39] R. Ineu, M. Pereira, M. Aschner, C. Nogueira, G. Zeni and J. Rocha. Food and chemical toxicology, 2008, 46, 3023-3029.

[40] E. Cadirci, H. Suleyman, H. Aksoy, Z. Halici, U. Ozgen, A. Koc and N. Ozturk. Chem Biol Interact, 2007, $170,40-8$.

[41] M.Y. Lee, I.S. Shin, W.Y. Jeon, C.S. Seo, H. Ha, J.I. Huh and H.K. Shin. J Ethnopharmacol, 2012, 142, 346-53.

[42] B. Halliwell. Free radical research, 1996, 25, 57-74.

[43] I. Alican, F. Toker, S. Arbak, B.Ç. Yeg̃en, A.S. Yalçin and Ş. Oktay. pharmacological Research, 1994, 30, 123-135.

[44] R.S. Devi, S. Narayan, G. Vani and C.S. Shyamala Devi. Chem Biol Interact, 2007, 167, 71-83.

[45] P. Chelikani, I. Fita and P.C. Loewen. Cellular and Molecular Life Sciences CMLS, 2004, 61, 192-208.

[46] A.F. de Bem, R. de Lima Portella, J. Perottoni, E. Becker, D. Bohrer, M.W. Paixão, C.W. Nogueira, G. Zeni and J.B.T. Rocha. Chemico-biological interactions, 2006, 162, 1-10.

[47] M. Ajitha. Ind Drugs, 2001, 38, 545-549.

[48] H.P. Toroudi, M. Rahgozar, A. Bakhtiarian and B. Djahanguiri. Scand J Gastroenterol, 1999, 34, 962-6.

[49] M.T. Nelson and J.M. Quayle. American Journal of Physiology-Cell Physiology, 1995, 268, C799-C822.
[50] S. GOSWAMI, S. JAIN and D. SANTANI. Journal of pharmacy and pharmacology, 1997, 49, 195-199.

[51] H.M. Patel, D.D. Santani and S.G. Goswami. Pharmacology, 2001, 63, 154-9.

[52] K. Sakai, M. Akima and I. Katsuyama. Jpn J Pharmacol, 1999, 79, 51-7. 